\title{
Serum Cholinesterase Level as a Biomarker in Detecting Liver Injury in Patients with Chronic Hepatitis C
}

\author{
Salem Soliman Ahmed Salama ${ }^{1}$, Bahy El-Deen El-Sayed El-Bahnasawy, \\ Mahmoud Abd Ellatif Hashish' ${ }^{2}$, Mustafa Mohammed Mustafa Al Ebiary*1 \\ ${ }^{1}$ Department of Internal Medicine, Faculty of Medicine, Al-Azhar University \\ ${ }^{2}$ Department of Clinical Pathology, Faculty of Medicine, Al-Azhar University \\ * Corresponding author: Mustafa Mohammed Mustafa Al Ebiary, \\ Mobile: (+20)01015665492, E-mail: alebiary2010@yahoo.com
}

\begin{abstract}
Background: hepatitis $\mathrm{C}$ virus can cause both acute and chronic hepatitis. The acute process is self-limited, rarely causes hepatic failure and usually leads to chronic infection. Chronic HCV infection often follows a progressive course over many years and can ultimately result in cirrhosis, HCC and the need for liver transplantation.

Objective: the aim of this study is to evaluate serum cholinesterase (CHE) level as a biomarker for detecting liver damage in patients with chronic hepatitis $\mathrm{C}$.

Patients and Methods: the current study was carried out on 50 subjects selected from the outpatient's clinic of Internal Medicine Department of Sayed Galal Hospital, Al-Azhar University and admitted to the internal department. The study was performed in the period between July-2014 to July -2019.

Results: Sensitivity of cholinesterase is $100 \%$, its specificity is $100 \%$ and its accuracy is $100 \%$, in predicting liver injury in patients with chronic hepatitis $\mathrm{C}$. Cholinesterase is positively correlated with $\mathrm{Hb}$, platelets and albumin. Cholinesterase is negatively correlated with ALT, AST and ALP, total \& direct bilirubin, PT, INR, urea, creatinine and AFP. There is significant increase of cholinesterase among compensated compared with decompensated cirrhotic patients. There is significant decrease of cholinesterase among compensated cirrhotic patients compared with controls. There is significant decrease of cholinesterase among decompensated cirrhotic patients compared with controls.

Conclusion: cholinesterase is an excellent biomarker of cirrhosis with good sensitivity and specificity. Cholinesterase shows good correlation with albumin, PT, INR and Child-Puch score. Cholinesterase distinguishes decompensated cirrhosis from compensated cirrhosis well.
\end{abstract}

Keywords: Cholinesterase, Liver, Hepatitis C virus

\section{INTRODUCTION}

Hepatitis $\mathbf{C}$ virus (HCV) can cause both acute and chronic hepatitis. The acute process is self-limited, rarely causes hepatic failure and usually leads to chronic infection. Chronic HCV infection often follows a progressive course over many years and can ultimately result in cirrhosis, hepatocellular carcinoma (HCC) and the need for liver transplantation ${ }^{(\mathbf{1})}$.

Cirrhosis of the liver is a frequently encountered disease ${ }^{(2)}$. Liver cirrhosis is a clinical condition wherein blemish tissue replaces normal tissue of the liver. As the healthy tissue is replaced by blotted tissue, there is an obstruction in the flow of blood through the liver affecting its function ${ }^{(3)}$. Liver cirrhosis rarely causes signs and symptoms in its early stage, but as liver deteriorations the signs and symptoms appear ${ }^{(4)}$.

Liver function tests (LFTs) that measures the level of serum liver enzymes usually reflects hepatocyte integrity or cholestasis rather than liver function ${ }^{(5)}$.

Five laboratory assays are commonly called liver function tests (serum alanine and aspartate transaminases, serum alkaline phosphatase, serum protein and albumin). These tests are neither specific to the liver nor true measures of liver functions ${ }^{(6)}$.
Cholinesterase is a family of enzymes that catalyze the hydrolysis of the neurotransmitter acetylcholine into choline and acetic acid ${ }^{(3)}$.

There are 2 types; Acetyl cholinesterase also known as erythrocyte cholinesterase found in RBCs cell membrane and pseudo-cholinesterase known as plasma cholinesterase which is synthesized mainly in hepatocyte and is released into blood and its activity is reduced in liver dysfunction due to reduced synthesis (7).

In contrast to cholinesterase activity, the activities of the other serum enzymes associated with clinical assessment of liver function, increase due to excessive release from this cellular source after cell membrane damage ${ }^{(3)}$.

In gastroenterology, the Child-Pugh score is used to assess the prognosis of chronic liver disease, mainly cirrhosis. Although originally used to predict mortality during surgery, this score is now used to determine the prognosis as well as the required strength of treatment and the necessity for liver transplantation ${ }^{(\mathbf{8})}$.

However, the cirrhotic patients particularly those with Child-Pugh grades $\mathbf{B}$ and $\mathbf{C}$ with ascites or hemorrhagic tendency are usually treated with albumin or blood transfusion which may affect the numerical value for calculating the Child-Pugh score. The serum cholinesterase is not easily affected by this 
treatment ${ }^{(9)}$. The commonly available tests used in assessing the severity of cirrhosis have certain drawbacks. However, serum cholinesterase level in detecting liver damage in chronic hepatitis $\mathbf{C}$ needs to be clarified.

\section{AIM OF THE WORK}

The aim of this study is to evaluate serum cholinesterase level as a biomarker for detecting liver damage in patients with chronic hepatitis $\mathbf{C}$.

\section{SUBJECTS AND METHODS}

\section{(I) Subjects:}

The current study was carried out on $\mathbf{5 0}$ subjects selected from the out patient's clinic of Internal Medicine Department of Sayed Galal Hospital, AlAzhar University and admitted to the internal department. The study was performed in the period between July-2014 to July -2019.

\section{They were divided into:}

Group 1: 20 Patients having compensated liver cirrhosis due to $\mathbf{H C V}$ infection.

Group 2: 20 Patients having decompensated liver cirrhosis due to $\mathbf{H C V}$ infection

Group 3: 10 Healthy subjects matched for age and sex as control group.

Exclusion criteria:

1-History of blood transfusion or albumin infusion 4 weeks prior to enrolment.

2-History and clinical evidence of variceal bleeding at enrolment.

3-History or evidence of HCC.

4-Liver transplantation.

5-Congenital liver disease.

6-Muscle dystrophy.

7-Pregnancy.

(II) Methods: The all subjects were subjected to the following:

(1) Full history taking.

(2) Clinical examination.

(3) Laboratory investigations.

(4) Fibro-Scan for assessment of degree of liver inflammation and fibrosis.

(5) AST platelet ratio index (APRI).

(6) Measurement of serum cholinesterase by DGKC method.

(7) Financial support: This work is not financially supported from any organization, society, institutes or government.

(9) Child-Turcotte-Pugh Score.

Ethical approval:

The study was approved by the ethics committee in Al-Azhar University Hospitals (ElHussein and Sayed Galal) and a written informed consent was obtained from each person.

\section{Statistical analysis of the data:}

Data were fed to the computer and analyzed using IBM SPSS software package version 20.0. (Armonk, NY: IBM Corp) Qualitative data were described using number and percent. The Kolmogorov-Smirnov test was used to verify the normality of distribution Quantitative data were described using range (minimum and maximum), mean, standard deviation and median. Significance of the obtained results was judged at the $\mathbf{5 \%}$ level.

The used tests were:

(1) - Chi-square test:

For categorical variables, to compare between different groups

(2) - Monte Carlo correction:

Correction for chi-square when $>\mathbf{2 0 \%}$ of the cells has expected count $<\mathbf{5}$

(3) - F-test (ANOVA):

For normally distributed quantitative variables, to compare between more than two groups, and Post Hoc test (Tukey) for pairwise comparisons

(4) - Pearson correlation coefficient:

It is a measure of the strength of the linear relationship between $\mathbf{2}$ variables. It is referred to as Pearson's correlation or simply as the correlation coefficient. Positive correlation indicates that both variables increase or decrease together, whereas negative correlation indicates that as one variable increases, so the other decreases and vice versa.

(5) - Mann Whitney test:

For abnormally distributed quantitative variables, to compare between 2 studied groups

(6) - Kruskal Wallis test:

For abnormally distributed quantitative variables, to compare between more than $\mathbf{2}$ studied groups and Post Hoc (Dunn's multiple comparisons test) for pairwise comparisons

(7) - Receiver operating characteristic curve (ROC): It is generated by plotting sensitivity (TP) on $\mathbf{Y}$ axis versus $\mathbf{1}$-specificity (FP) on $\mathbf{X}$ axis at different cut off values. The area under the ROC curve denotes the diagnostic performance of the test. Area $>\mathbf{5 0 \%}$ gives acceptable performance and area about $100 \%$ is the best performance for the test. The ROC curve allows also a comparison of performance between 2 tests.

(8) - Sensitivity:

The capacity of the test to correctly identify diseased individuals in a population 'TRUE POSITIVES', the greater the sensitivity, the smaller the number of unidentified case 'false negatives'

(9) - Specificity:

The capacity of the test to correctly exclude individuals who are free of the disease 'TRUE NEGATIVES', the greater the specificity, the fewer 'false positives' will be included 
(10) - Positive Predictive value (PPV):

The probability of the disease being present, among those with positive diagnostic test results

(11) - Negative Predictive value (NPV):

The probability that the disease was absent, among those whose diagnostic test results were negative

- Insignificant: if $\mathbf{P}$ - value $>\mathbf{0 . 0 5}$

- Significant: if P-value $\leq \mathbf{0 . 0 5}$

\section{RESULTS}

The current study included 50 subjects; they were divided into:

-Group (1): 20 Patients had compensated cirrhosis due to $\mathbf{H C V}$ infection

- Group (2): 20 Patients had decompensated cirrhosis due to $\mathbf{H C V}$ infection

- Group (3): 10 Healthy subjects matched for age and sex as controls

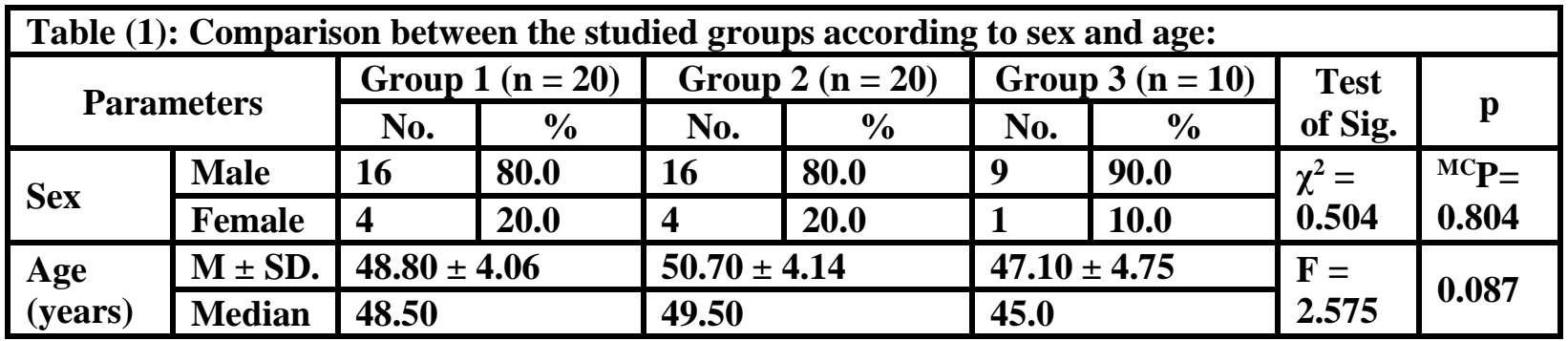

$\chi^{2}$ : Chi square test MC: Monte Carlo $\quad F$ : $F$ for ANOVA test

-There are insignificant differences between the studied groups as regards sex and age.

Table (2): Comparison between the studied groups according to risk factors:

\begin{tabular}{|c|c|c|c|c|c|c|c|c|}
\hline & \multicolumn{2}{|c|}{ Group 1(n= 20) } & \multicolumn{2}{|c|}{ Group 2 $(n=20)$} & \multicolumn{2}{|c|}{ Group $3(n=10)$} & \multirow[t]{2}{*}{$\chi^{2}$} & \multirow[t]{2}{*}{$\mathbf{p}$} \\
\hline & No. & $\%$ & No. & $\%$ & No. & $\%$ & & \\
\hline Alcohol drinking & $\mathbf{0}$ & 0.0 & 0 & 0.0 & 0 & 0.0 & - & - \\
\hline Smoking & 5 & 25.0 & 4 & 20.0 & 4 & 40.0 & 1.403 & 0.496 \\
\hline DM & 4 & 20.0 & 4 & 20.0 & $\overline{\mathbf{0}}$ & 0.0 & 2.216 & ${ }^{\mathrm{MC}} \mathrm{P}=0.325$ \\
\hline HTN & 3 & 15.0 & 1 & 5.0 & $\mathbf{0}$ & 0.0 & 1.786 & ${ }^{{ }^{M C}} \mathrm{P}=0.518$ \\
\hline Blood transfusion & $\mathbf{0}$ & 0.0 & $\mathbf{0}$ & 0.0 & $\mathbf{0}$ & 0.0 & - & - \\
\hline IV. Albumin & $\mathbf{0}$ & $\overline{0.0}$ & $\mathbf{0}$ & $\overline{0.0}$ & $\overline{\mathbf{0}}$ & $\overline{0.0}$ & - & - \\
\hline
\end{tabular}

$\chi^{2}$ : Chi square test MC: Monte Carlo

-There are insignificant differences between the studied groups as regards these risk factors.

\begin{tabular}{|l|c|c|c|c|}
\hline \multicolumn{5}{|c|}{ Table (3): Comparison between group-1 and group-2 according to HCV-PCR: } \\
\hline HCV-PCR (IU/mL) & Group 1 $(\mathrm{n}=\mathbf{2 0})$ & Group $2(\mathbf{n}=\mathbf{2 0})$ & $\mathrm{U}$ & P \\
\hline $\mathrm{M} \pm$ SD. & $\mathbf{7 1 6 9 0 7 . 0} \pm 162284.54$ & $516053.0 \pm 116688.3$ & \multirow{2}{*}{192.0} & \multirow{2}{*}{0.841} \\
\hline Median & $\mathbf{3 6 1 9 3 9 . 0}$ & $\mathbf{4 9 8 6 8 6 . 0}$ & & \\
\hline
\end{tabular}

U: Mann Whitney test

-There is insignificant difference between group-1 and group-2 as regards HCV-PCR.

\begin{tabular}{|c|c|c|c|c|c|c|c|c|}
\hline Table (4): Com & rison b & een the & tudied $g$ & ups ac & ording & differe & paramet & \\
\hline Parameters & Grour & $(\mathrm{n}=20)$ & Grou & $2(n=$ & Gro & $\begin{array}{l}\text { p3(n }= \\
\text { (0) }\end{array}$ & $\chi^{2}$ & $\mathbf{p}$ \\
\hline & No. & $\%$ & No. & $\%$ & No. & $\%$ & & \\
\hline HCV infection & 20 & 100.0 & 20 & 100.0 & 0 & 0.0 & $41.713^{*}$ & ${ }^{{ }^{M C}} \mathbf{P}<0.0011^{*}$ \\
\hline Ascites & $\mathbf{0}$ & 0.0 & 20 & 100.0 & $\mathbf{0}$ & 0.0 & 50.000* & $<0.001^{*}$ \\
\hline Edema & $\mathbf{0}$ & 0.0 & 20 & 100.0 & $\mathbf{0}$ & 0.0 & $50.000^{*}$ & $<0.001^{*}$ \\
\hline HE & $\mathbf{0}$ & 0.0 & 9 & 45.0 & $\mathbf{0}$ & $\overline{0.0}$ & $14.989^{*}$ & ${ }^{\mathrm{MC}} \mathbf{P}<0.001^{*}$ \\
\hline Liver cirrhosis & 20 & 100.0 & 20 & 100.0 & $\mathbf{0}$ & 0.0 & 41.713* $^{*}$ & ${ }^{\mathrm{MC}} \mathrm{P}<0.001^{*}$ \\
\hline Splenomegaly & 15 & 75.0 & 20 & 100.0 & $\mathbf{0}$ & 0.0 & 32.143* $^{*}$ & $<0.001^{*}$ \\
\hline
\end{tabular}

$\chi^{2}$ : Chi square test MC: Monte Carlo

Table (5): Comparison between the studied groups according to $\mathrm{CBC}$ : 


\begin{tabular}{|c|c|c|c|c|c|c|}
\hline \multicolumn{2}{|r|}{$\mathrm{CBC}$} & Group $1(n=20)$ & Group $2(n=20)$ & Group $3(n=10)$ & $\mathbf{F}$ & $\mathbf{P}$ \\
\hline \multirow{3}{*}{ WBCs } & $\mathrm{M} \pm \mathrm{SD}$ & $5125.0 \pm 1060.7$ & $4385.0 \pm 950.5$ & $7790.0 \pm 1342.0$ & \multirow{2}{*}{ 33.979* } & \multirow{2}{*}{$<0.001^{*}$} \\
\hline & Median & 5200.0 & 4250.0 & 7650.0 & & \\
\hline & Sig.bet.groups & \multicolumn{5}{|c|}{$P_{1}=0.087, P_{2}<0.001^{*}, P_{3}<0.001^{*}$} \\
\hline \multirow{3}{*}{$\mathbf{H b}$} & $\mathrm{M} \pm \mathrm{SD}$ & $11.06 \pm 1.44$ & $9.24 \pm 0.73$ & $13.02 \pm 0.85$ & \multirow{2}{*}{$41.656^{*}$} & \multirow{2}{*}{$<0.001^{*}$} \\
\hline & Median & 10.75 & 9.25 & 12.85 & & \\
\hline & Sig.bet.groups & \multicolumn{5}{|c|}{$\mathrm{P}_{1}<0.001^{*}, \mathrm{P}_{2}<0.001^{*}, \mathrm{P}_{3}<0.001^{*}$} \\
\hline \multirow{3}{*}{ Plat. } & $\mathrm{M} \pm \mathrm{SD}$ & $139.56 \pm 31.76$ & $89.40 \pm 5.37$ & $227.60 \pm 32.71$ & \multirow{2}{*}{ 73.047* } & \multirow{2}{*}{$<0.001 *$} \\
\hline & Median & 141.0 & 87.50 & 227.0 & & \\
\hline & Sig.bet.groups & \multicolumn{5}{|c|}{$P_{1}<0.001^{*}, P_{2}<0.001^{*}, P_{3}<0.001^{*}$} \\
\hline
\end{tabular}

F: F for ANOVA test, Pairwise comparison between each 2 groups was done using Post Hoc Test (Tukey)

$\mathrm{P}_{1}$ : $\mathrm{P}$ value for comparing between group 1 and group $2, \quad \mathrm{P}_{2}$ : $\mathrm{P}$ value for comparing between group 1 and group 3

$\mathrm{P}_{3}$ : $\mathrm{P}$ value for comparing between group 2 and group 3

-There is insignificant decrease of WBCs among group 2 compared with group 1

-There is significant decrease of WBCs, $\mathrm{Hb}$ and platelets among group 1 compared with group 3

-There is significant decrease of WBCs, $\mathrm{Hb}$ and platelets among group 2 compared with group 3

-There is significant increase of $\mathrm{Hb}$ and platelets among group 1 compared with group 2

\begin{tabular}{|c|c|c|c|c|c|c|}
\hline Liver & function & Group $1(n=20)$ & Group $2(n=20)$ & Group $3(n=10)$ & Test of sig. & $\mathbf{P}$ \\
\hline & $\mathrm{M} \pm \mathrm{SD}$ & $50.20 \pm 10.95$ & $48.85 \pm 3.10$ & $31.60 \pm 4.45$ & & \\
\hline AST (U/L) & Median & 48.0 & 46.0 & 32.0 & $10.642^{*}$ & $0.001^{*}$ \\
\hline & Sig.bet.grps & $P_{1}=0.921, P_{2}<0$ & $001^{*}, P_{3}=0.001^{*}$ & & & \\
\hline & $\mathrm{M} \pm \mathrm{SD}$ & $42.20 \pm 10.16$ & $43.05 \pm 10.09$ & $23.20 \pm 5.87$ & $H=$ & \\
\hline ALT & Median & 37.0 & 42.50 & 21.50 & $19.073^{*}$ & $0.001^{*}$ \\
\hline & Sig.bet.grps & $P_{1}=0.672, P_{2}<0$. & $01^{*}, P_{3}<0.001^{*}$ & & & \\
\hline & $\mathrm{M} \pm \mathrm{SD}$ & $145.3 \pm 28.35$ & $146.0 \pm 23.07$ & $74.70 \pm 10.17$ & $\mathbf{F}=$ & \\
\hline $\begin{array}{l}\mathbf{A L P} \\
(\mathbf{U} / \mathbf{I})\end{array}$ & Median & 143.0 & 144.0 & 71.50 & 35.912* & $0.001^{*}$ \\
\hline & Sig.bet.grps & $P_{1}=0.995, P_{2}<0$. & $01^{*}, P_{3}<0.001^{*}$ & & & \\
\hline & $\mathrm{M} \pm \mathrm{SD}$ & $3.68 \pm 0.18$ & $2.85 \pm 0.13$ & $4.27 \pm 0.35$ & $\mathbf{F}=$ & \\
\hline Albumin & Median & 3.60 & 2.90 & 4.18 & 173.507* & $0.001^{*}$ \\
\hline & Sig.bet.grps & $P_{1}<0.001^{*}, P_{2}<0$ & $001^{*}, P_{3}<0.001^{*}$ & & & \\
\hline & $\mathrm{M} \pm \mathrm{SD}$ & $13.30 \pm 1.46$ & $19.14 \pm 1.84$ & $11.82 \pm 0.53$ & $\mathbf{F}=$ & \\
\hline PT & Median & 13.35 & 19.05 & 11.80 & 108.404* & $0.001^{*}$ \\
\hline & Sig.bet.grps & $\mathrm{P}_{1}<0.001^{*}, \mathrm{P}_{2}<0$ & $001^{*}, P_{3}<0.001^{*}$ & & & \\
\hline
\end{tabular}

F: F for ANOVA test, Pairwise comparison between each 2 groups was done using Post Hoc Test (Tukey)

$\mathrm{H}$ : $\mathrm{H}$ for Kruskal Wallis test, Pairwise comparison between each 2 groups was done using Post Hoc Test (Dunn's for multiple comparisons test), $\mathrm{P}_{1}$ : $\mathrm{P}$ value for comparing between group 1 and group $2, \mathrm{P}_{2}$ : $\mathrm{P}$ value for comparing between group 1 and group $3, \mathrm{P}_{3}$ : $\mathrm{P}$ value for comparing between group 2 and group 3

\begin{tabular}{|c|c|c|c|c|c|c|}
\hline \multicolumn{2}{|c|}{ Parameters } & Group $1(n=20)$ & Group $2(n=20)$ & Group $3(n=10)$ & $\mathbf{F}$ & $\mathbf{p}$ \\
\hline \multirow{3}{*}{$\begin{array}{l}\text { T.bilirubin } \\
\text { (mg/dl) }\end{array}$} & $\mathrm{M} \pm \mathrm{SD}$ & $1.34 \pm 0.25$ & $3.03 \pm 0.93$ & $0.84 \pm 0.14$ & \multirow{2}{*}{$\begin{array}{l}56.50 \\
9^{*}\end{array}$} & \multirow{2}{*}{$\begin{array}{l}< \\
0.001^{*}\end{array}$} \\
\hline & Median & 1.30 & 3.15 & 0.85 & & \\
\hline & Sig.bet.grps & \multicolumn{3}{|c|}{$P_{1}<0.001^{*}, P_{2}=0.104, P_{3}<0.001^{*}$} & & \\
\hline \multirow{3}{*}{$\begin{array}{l}\text { D. bilirubin } \\
\text { (mg/dl) }\end{array}$} & $\mathrm{M} \pm \mathrm{SD}$ & $0.57 \pm 0.07$ & $1.66 \pm 0.23$ & $0.16 \pm 0.07$ & \multirow{3}{*}{$\begin{array}{l}52.92 \\
8^{*}\end{array}$} & \multirow{3}{*}{$\begin{array}{l}< \\
0.001^{*}\end{array}$} \\
\hline & Median & 0.60 & 1.50 & 0.14 & & \\
\hline & Sig.bet.grps & \multicolumn{3}{|c|}{$P_{1}<0.001^{*}, P_{2}=0.045^{*}, P_{3}<0.001^{*}$} & & \\
\hline
\end{tabular}

F: F for ANOVA test, Pairwise comparison between each 2 groups was done using Post Hoc Test (Tukey) $\mathrm{P}_{1}$ : $\mathrm{P}$ value for comparing between group 1 and group $2, \mathrm{P}_{2}$ : $\mathrm{P}$ value for comparing between group 1 and group 3 $\mathrm{P}_{3}$ : $\mathrm{P}$ value for comparing between group 2 and group 3

Table (8): Comparison between the studied groups according to INR and AFP: 
ejhm.journals.ekb.eg

\begin{tabular}{|c|c|c|c|c|c|c|}
\hline \multicolumn{2}{|c|}{ Parameters } & Group $1(n=20)$ & Group 2 $(n=20)$ & Group $3(n=10)$ & Test of sig. & $\mathbf{P}$ \\
\hline \multirow{3}{*}{ INR } & $\mathrm{M} \pm \mathrm{SD}$ & $1.22 \pm 0.18$ & $1.70 \pm 0.18$ & $1.04 \pm 0.08$ & \multirow{2}{*}{$\begin{array}{l}\mathrm{F}= \\
66.746^{*}\end{array}$} & \multirow{2}{*}{$\begin{array}{l}< \\
0.001^{*}\end{array}$} \\
\hline & Median & 1.25 & 1.71 & 1.05 & & \\
\hline & Sig.bet.Grps & \multicolumn{3}{|c|}{$P_{1}<0.001^{*}, P_{2}=0.017^{*}, P_{3}<0.001^{*}$} & & \\
\hline \multirow{3}{*}{$\begin{array}{l}\text { AFP } \\
(\mathbf{n g} / \mathrm{ml})\end{array}$} & $\mathbf{M} \pm \mathrm{SD}$ & $5.61 \pm 1.09$ & $9.23 \pm 1.12$ & $2.57 \pm 0.84$ & \multirow{2}{*}{$\begin{array}{l}\mathbf{H}= \\
25.356^{*}\end{array}$} & \multirow{2}{*}{$\begin{array}{l}< \\
0.001 *\end{array}$} \\
\hline & Median & 4.45 & 7.10 & 2.55 & & \\
\hline & Sig.bet.Grps & \multicolumn{3}{|c|}{$P_{1}=0.023^{*}, P_{2}=0.002^{*}, P_{3}<0.001^{*}$} & & \\
\hline
\end{tabular}

F: F for ANOVA test, Pairwise comparison between each 2 groups was done using Post Hoc Test (Tukey)

$\mathrm{H}$ : $\mathrm{H}$ for Kruskal Wallis test, Pairwise comparison between each 2 groups was done using Post Hoc Test (Dunn's for multiple comparisons test), $\mathrm{P}_{1}$ : $\mathrm{P}$ value for comparing between group 1 and group 2, $\mathrm{P}_{2}: \mathrm{P}$ value for comparing between group 1 and group 3, $\mathrm{P}_{3}$ : $\mathrm{P}$ value for comparing between group 2 and group 3

\begin{tabular}{|c|c|c|c|c|c|}
\hline \multicolumn{6}{|c|}{ Table (9): Comparison between group-1 and group-2 according to serum cholinesterase results: } \\
\hline Cholinesterase (IU/L) & Group $1(n=20)$ & Group 2 $(n=20)$ & Group $3(n=10)$ & $\mathbf{F}$ & $\mathbf{p}$ \\
\hline Range & $3194.3-3798.2$ & $1642.7-2725.2$ & 6214.0 - 9182.0 & \multirow{3}{*}{$317.587^{*}$} & \multirow{3}{*}{$<0.001 *$} \\
\hline $\bar{M} \pm \mathrm{SD}$ & $3437.6 \pm 173.5$ & $2209.2 \pm 367.3$ & $7683.94 \pm 1153.10$ & & \\
\hline Median & 3416.1 & 2255.6 & 7680.23 & & \\
\hline Sig.bet.Grps & \multicolumn{3}{|c|}{$\mathrm{P}_{1}<0.001^{*}, \mathrm{P}_{2}<0.001^{*}, \mathrm{P}_{3}<0.001^{*}$} & & \\
\hline
\end{tabular}

F: F for ANOVA test, Pairwise comparison between each 2 groups was done using Post Hoc Test (Tukey)

$P_{1}$ : $P$ value for comparing between group 1 and group 2

$P_{2}$ : $P$ value for comparing between group 1 and group 3

$P_{3}$ : $P$ value for comparing between group 2 and group 3

-There is significant increase of cholinesterase among group 1 compared with group 2

-There is significant decrease of cholinesterase among group 1 compared with group 3

-There is significant decrease of cholinesterase among group 2 compared with group 3

\begin{tabular}{|c|c|c|c|c|c|c|c|c|}
\hline Table (10): $R$ & curv & differ & arameter & liagnose & hotics fror & ontrols & & \\
\hline Parameters & AUC & $\mathbf{P}$ & $95 \%$ CI & Cutt off & Sensitivity & Specificity & PPV & NPV \\
\hline Cholinesterase & 1.000 & $<0.001^{*}$ & 1.0 - 1.0 & $\leq 3798.24$ & 100.0 & 100.0 & 100.0 & 100.0 \\
\hline APRI & 0.999 & $<0.001^{*}$ & $0.93-1.0$ & $>0.5$ & 97.50 & 100.0 & 100.0 & 90.9 \\
\hline
\end{tabular}

AUC: Area under curve

$P$ value: Probability value

CI: Confidence Intervals

NPV: Negative predictive value

PPV: Positive predictive value

\begin{tabular}{|l|l|l|l|l|l|l|l|l|}
\hline \multicolumn{7}{|c|}{ Table (11): ROC curve for different parameters to diagnose of compensated from decompensated cirrhotcis } \\
\hline Parameters & AUC & P & 95 \%CI & Cutt off & Sensitivity & Specificity & PPV & NPV \\
\hline Cholinesterase & $\mathbf{1 . 0 0 0}$ & $<\mathbf{0 . 0 0 1}^{*}$ & $\mathbf{1 . 0}-\mathbf{1 . 0}$ & $\mathbf{2 7 2 5 . 2 3}$ & $\mathbf{1 0 0 . 0}$ & $\mathbf{1 0 0 . 0}$ & $\mathbf{1 0 0 . 0}$ & $\mathbf{1 0 0 . 0}$ \\
\hline APRI & $\mathbf{0 . 8 1 0}$ & $<\mathbf{0 . 0 0 1}^{*}$ & $\mathbf{0 . 6 6}-\mathbf{0 . 9 2}$ & $\leq 1.2$ & $\mathbf{9 0 . 0}$ & $\mathbf{6 5 . 0}$ & $\mathbf{7 2 . 0}$ & $\mathbf{8 6 . 7}$ \\
\hline
\end{tabular}

AUC: Area under curve

P value: Probability value

CI: Confidence Intervals

NPV: Negative predictive value

PPV: Positive predictive value

\section{DISCUSSION}

The aim of the current study is to evaluate serum CHE level as a biomarker for detecting liver injury in patients with CHC. For this purpose; 50 subjects ( 20 patients had compensated cirrhosis, 20 patients had decompensated cirrhosis and 10 healthy persons as controls) were selected.

All the studied subjects were subjected to full history taking, throughout clinical examination, laboratory investigations including; CBC, AST, ALT, serum total and direct bilirubin, serum albumin, ALP,
PT and INR, urea and creatinine, AFP, HCVantibodies and HVC-RNA by PCR and measurement of serum cholinesterase, liver fibroscan and APRI test.

The mean age of controls is $\mathbf{4 7}$ years old which is not significantly different from the other studied groups. Male sex was representing the majority in all groups.

In this study HCV-RNA level is lower in patients with end-stage $\mathbf{H C V}$-related liver cirrhosis than compensated cirrhosis and this is matched with study done by Duvoux et al. ${ }^{(10)}$. 
In the present study serum albumin level is significantly lower in decompensated patients more than compensated patients as compared with controls. Also, PT is prolonged in decompensated more than compensated cirrhotic patients also as compared with controls.

Serum bilirubin level show statistically significance increase among decompensated cirrotic patients compared with either compensated cirrhptic patients or controls.

In this work there is a significant negative correlation between serum cholinesterase levels and ALT, AST, ALP, PT, INR, bilirubin and AFP levels respectively, while there is a positive correlation between serum cholinesterase and serum albumin level.

AFP level increased significantly in compensated and decompensated groups as compared to controls and this agree with the study done by Chu et al. (11) who found that the severity of fibrosis/cirrhosis was significant predictors of elevated serum AFP and that higher serum AFP levels were significantly correlated with advanced fibrosis /cirrhosis in patients with chronic HCV.

In the current study APRI $<0.5$ identified healthy controls from compensated cirrhosis with sensitivity of APRI is $\mathbf{9 7 . 5} \%$ and its specificity is $\mathbf{1 0 0} \%$ and APRI $\leq \mathbf{1 . 2}$ can identified compensated cirrhotics from decompensated cirrhotics with sensitivity of APRI is $90 \%$ and its specificity is $65 \%$. But many conditions lead to elevated of liver transaminases that infelunce estimation of APRI score; for example, thyroid disorders and celiac sprue have been associated with elevated transaminase levels ${ }^{\left({ }^{12}\right)}$. Hemolysis and strenuous exercise should be considered also ${ }^{(\mathbf{1 3})}$.

In the present study cirrhotics are found to have significantly lower levels of serum CHE compared with the controls and the lower levels were correlated with Child Score such patients. These results were matched with those obtained by Meng $\boldsymbol{e t}$ al. ${ }^{(9)}$ who found serum CHE were low in various Child-Pugh score groups. The cirrhotic patients were strictly grouped into the $\mathbf{A}, \mathbf{B}$ and $\mathbf{C}$ groups, based on their Child-Pugh score. The results showed that serum CHE tended to decrease significantly in the $\mathbf{3}$ grades: Child A (5368.04 \pm 1657.32 U/I), Child B $(2943.06 \pm$ 1212.84 U/I) and Child C (1832.51 $\pm 710.68 \mathrm{U} / \mathrm{l})$. Difference between CHE activity in the Child A, B and $\mathbf{C}$ groups was statistically significant, as was the difference between the mean values for the Child B and $\mathbf{C}$ groups.

In the current study patients with liver cirrhosis have significantly lower levels of serum CHE compared with the controls and the lower levels were correlated with Child-Pugh Score such patients.

Similarly, Amany et al. ${ }^{(14)}$ found highly significant decrease in serum CHE levels in decompensated patients compared with compensated patien and serum $\mathbf{C H E}$ level at $\leq \mathbf{4 2 1 0} \mathbf{u} / \mathbf{l}$ (cutoff) can diagnose compensated cirrhosis by $\mathbf{8 6 . 6 7 \%}$ sensitivity, $100 \%$ specificity, $\mathbf{1 0 0 \%}$ PPV and $\mathbf{8 8 . 2 4 \%}$ NPV, while, seum CHE serum at $\leq \mathbf{2 1 5 2}$ u/l (cutoff) can diagnose decompensated cirrhosis by $\mathbf{9 3 . 3 3 \%}$ sensitivity, $100 \%$ specificity, $\mathbf{1 0 0 \%}$ PPV and $\mathbf{9 3 . 7 5 \%}$ NPV.

In this study, the mean serum CHE was 3437.6 \pm 173.5 IU/L in compensated cirrhotic patients, 2209.2 \pm 367.3 in decompensated cirrhotic patients and was 7683.94 \pm 1153.10 in controls.

This is in agreement with a study conducted by Ramachandran et al. ${ }^{(15)}$ who found the median serum CHE level in cirrhotics was 1595 IU/L $(110$ - 8143) compared with $7892(2022$ - 21673) in controls and the median level of compensated cirrhotic patients was 4246 (680 - 8143) compared with 7892 (2022- 21673) in controls and also found the median level in decompensated cirrhotic patients was $\mathbf{1 3 2 4}$ (110 - 4550) compared with compensated cirrhotic patients was $4246(680-8143)$ and found that serum CHE levels below 3506 had a $\mathbf{9 8 . 7 \%}$ sensitivity and 80.3\% specificity in predicting cirrhosis. They concluded that serum CHE is an excellent biomarker of cirrhosis with good sensitivity and specificity.

Varsha ${ }^{(16)}$ made a study on serum CHE as important diagnostic marker to distinguish between liver diseases (hepatits, cirrhosis, obstructive jaundice, liver abcess and liver mass) and non-liver diseases (dermatitis, acute respiratory failure, cellulitis, bone diseases, renal failure, anasrca and COPD) and they found that serum CHE levels were decreased in liver disease patients only, as compared with levels of conventional liver function tests which are decreased in both group of patients thereby showing that serum CHE assay has much more significance to diagnose liver disease patients.

Thus it can be stated that serum CHE alone can be very helpful to distinguish liver diseases from non-liver disease. It is $\mathbf{9 4 . 7 \%}$ sensitive and $\mathbf{1 0 0 \%}$ specific, thereby suggesting that serum CHE activity strongly indicate liver dysfunctions.

In the current study; the cut off value to diagnose compensated cirrhosis from controls is $\leq$ 3798.24 $\mathrm{U} / \mathrm{l}$ and the cut off value to diagnose decompensated cirrhosis from compensated cirrhosis $<2725.23$ with $100 \%$ sensitivity and $100 \%$ specificity; while Ramachandran et al. ${ }^{(15)}$ found that CHE level was $<\mathbf{2 3 8 5}$ IU/L had $\mathbf{8 0 . 1 \%}$ sensitivity and $\mathbf{8 8 . 2 \%}$ specificity in predicting decompensated cirrhosis.

In this study it is found that the cirrhotics have significantly lower levels of serum CHE as compared with healthy controls. Also it is found that patients with decompensated cirrhosis have significantly lower levels compared with compensated cirrhosis. 
Serum levels of CHE showed excellent positive correlation with serum albumin levels in the current study. These results were matched with those concluded by Mohamed et $\boldsymbol{a l} .{ }^{(3)}$. Moreover, serum level of CHE is negatively correlated with PT, which is in agreement with the study done by Mohamed $\boldsymbol{e t}$ al. ${ }^{(3)}$.

\section{CONCLUSION}

- There is association between cholinesterase and liver disorders, viral hepatitis and liver cirrhosis.

- Cholinesterase can be used as a routine diagnostic test besides other liver function tests for investigation of liver disorders.

- Cholinesterase is an excellent biomarker of cirrhosis with good sensitivity and specificity.

- Cholinesterase shows good correlation with albumin, PT, INR and Child-Puch score.

- Cholinesterase distinguishes decompensated cirrhosis from compensated cirrhosis well.

- Low levels of cholinesterase in cirrhosis may serve as a useful prognostic marker of advanced liver disease.

- The level of cholinesterase is closely correlated with the severity of liver damage and correlated also with the Child-Pugh score.

- Combination of cholinesterase with Child-Pugh score may be more objective and accurate in evaluating the liver reserve function of cirrhotic patients.

- Cholinesterase level reflects liver cell conditions; where low levels indicate hepatocellular damage.

\section{RECOMMENDATION}

- Long-term follow-up studies are warranted to define cholinesterase exact role in clinical practice.

\section{REFERENCES}

1. Chopra S, Pockros P (2017): Overview of management of chronic $\mathrm{HCV}$ infection. $\mathrm{Up}$ to date. http://www.uptodate.com.

2. Ramachandran J, Sajith K, Priya S et al. (2014): Serum cholinesterase is an excellent biomarker of liver cirrhosis. Trop Gastroenterol., 35(1): 15 - 20.
3. Mohamed N, Amanullah M, Amanvermez R et al. (2017): Serum cholinesterase as liver function test in cirrhotic patients at Soba Teaching hospital, Khartoum, Sudan. Int Res J Med Med Sci., 5(3): 44 - 49.

4. Bishop M, Edward E (2010): Clinical Chemistry; sixth edition; Lippincott Williams and Willinks; Baltimore, Philadephia, Pp. 522, 238.

5. Giannini E, Testa R, Savarino V et al. (2005): Liver enzyme alteration: a guide for clinicians. CMAJ., 172: 3: $367-379$.

6. Kumar T, Keerthana B (2016): Serum CHE as biomarker in liver disorders. Int J App Res., 2(7): 563 565.

7. Yanai M, Hoshino T (2010): Pseudocholinesterase (PCHE). Rinsho Byori., 116: 45 - 51.

8. Kariyone K, Shimatani Y, Kurihara T et al. (2010): Establishing indicators for diagnosis of cholinergic crisis. Rinsho Byori., 58: 10: 972 - 978.

9. Meng F, Yin X and Ma X et al. (2013): Assessment of the value of serum cholinesterase as a liver function test for cirrhotic patients. Biomed Rep., 1(2): 265 - 268.

10.Duvoux C, Pawlotsky J, Bastie A et al. (1999): Low HCV replication levels in end-stage hepatitis $\mathrm{C}$ virusrelated liver disease. J Hepatol., 31(4):593 - 597.

11. Chu C, Hwang S, Luo J et al. (2010): Clinical, virologic and pathologhic significance of elevated serum alphafetopritein levels in patients with chronic hepatitis C. J Clin Gastroent., 32(3): 240 - 244.

12. Cobbold J, Anstee Q, Thomas H (2010): Investigating mildly abnormal serum aminotransferase values. BMJ., 341:4039-45.

13.Pettersson J, Hindorf U, Persson $P$ et al. (2008): Muscular exercise can cause highly pathological liver function tests in healthy men. Br J Clin Pharmacol., 65(2):253 - 259.

14. Amany M, Elsaeed and Ismail $S$ et al. (2016): Serum kallistatin and CHE as biomarkers for the diagnosis of liver cirrhosis in patients with HCV infection. J CMD., 6(6): 143-152.

15. Ramanathan K, Sujatha N (2017): A Study on serum cholinesterase as a biomarker for cirrhosis of the Liver. JMSCR., 08: 26820-26827.

16. Varsha C (2014): Serum CHE as important diagnostic marker to distinguish between liver diseases and non liver diseases. Jemds., 3(19):5141- 5156. 